\author{
S. A. Demchenko ${ }^{1}$, Yu. A. Fedchenkova², L. S. Bobkova ${ }^{1}$, L. P. Artemchuk', \\ A. M. Demchenko ${ }^{1,2}$ \\ ${ }^{1}$ Institute of Pharmacology and Toxicology of National Academy of Medical Sciences Ukraine. \\ E-mail: demch7758@ukr.net \\ ${ }^{2}$ Nizhyn Mykola Gogol State University.
}

\title{
The synthesis and the study of the antitumor activity of 1,4-diaryl-5,6,7,8-tetrahydro-2,2a,8a triazacyclopenta[cd]azulene derivatives
}

Aim. To synthesize, prove the structural framework and study the antitumor activity of 1,4-diaryl-5,6,7,8tetrahydro-2,2a,8a-triazacyclopenta [cd]azulene derivatives.

Results and discussion. To determine the antineoplastic activity of 1-phenyl-4-aryl-5,6,7,8-tetrahydro2,2a,8a-triazacyclopenta[cd]azulenes 7a-g and 1-(41-bromophenyl)-4-aryl-5,6,7,8-tetra-hydro-2,2a,8a-triazacyclopenta [cd]azulenes $\mathbf{7 h - k}$ the study in vitro was carried out on 60 lines of cancer cells (leukemia, non-small cell lung cancer, colon cancer, CNS cancer, melanoma, ovarian cancer, renal cancer, prostate cancer and breast cancer) under the effect of the substance in the concentration of $10^{-5} \mathrm{~mol} / \mathrm{l}$ according to the standard procedure of the mitotic activity assessment of the new potential bioactive compounds by the fluorescent coloring method (sulphorhodamine B as a dye) performed in the US National Institute of cancer within the Development Therapeutic Program.

Experimental part. 2-Methoxy-3,4,5,6-tetrahydro- $7 \mathrm{H}$-azepine was obtained by alkylation of caprolactam with dimethyl sulfate. 3-Phenyl or (41'-bromophenyl)-(6,7,8,9-tetrahydro-5H-[1,2,4]triazolo[4,3-a]azepine 4 a,b was obtained by condensation of 2-methoxy-3,4,5,6-tetrahydro-7H-azepine 1 with 4-bromobenzoic acid hydrazide and subsequent cyclization of the intermediate product. The ${ }^{1} \mathrm{H}-\mathrm{NMR}$ spectra were recorded on a Bruker VXR-300 spectrometer (Germany) with the working frequency of $299.945 \mathrm{MHz}$, in DMSO- $\mathrm{d}_{6}$ using tetramethylsilane (TMS) as an internal standard. The purity of the compounds synthesized was controlled by TLC on the Silufol UV-254 plates in the system of chloroform - methanol $(9: 1)$.

Conclusions. New chemical compounds - derivatives of 1-phenyl(41-bromphenyl)-4-aryl-5,6,7,8-tetrahydro$2,2 a, 8 a-t r i a z a-c y c l o p e n t a[c d]$ azulene have been synthesized. The anticancer activity of the compounds obtained on 60 lines of tumor cells in the US National Cancer Institute has been studied. The high-active compounds that exhibit high levels of the antitumor activity have been identified.

Key words: 1,4-diaryl-5,6,7,8-tetrahydro-2,2a,8a-triazacyclopenta[cd]azulenes; antitumor activity

\section{С. А. Демченко, Ю. А. Федченкова, Л. С. Бобкова, Л. П. Артемчук, А. М. Демченко}

Синтез та вивчення протипухлинної активності похідних 1,4-діарил-5,6,7,8-тетрагідро2,2a,8а-триазациклопента[сd]азуленів

Мета роботи - синтезувати, довести структурну будову та провести вивчення протипухлинної активності похідних 1,4-діарил-5,6,7,8-тетрагідро-2,2а,8а-триазациклопента[сd]азуленів.

Результати та їх обговорення. Для визначення протипухлинної активності 1-среніл-4-арил-5,6,7,8тетрагідро-2,2а,8а-триазациклопента[сd]азулену 7a-g та 1-(41-бромфеніл)-4-арил-5,6,7,8-тетрагідро-2,2а,8атриазациклопента[cd]азулену 7h-k дослідження проведено in vitro на 60 лініях ракових клітин (лейкемії, легень, товстого кишківника, ЦНС, меланоми, яєчників, нирок, простати, молочної залози) при дії речовини в концентрації 10-5 моль/л за стандартною процедурою оцінки мітотичної активності нових потенційних біологічно активних сполук методом флуоресцентного зафрарбування (барвник - сульфородамін Б), виконаних у Національному інституті раку США (National Cancer Institute of Health, USA) в рамках Development Therapeutic Program.

Експериментальна частина. 2-Метокси-3,4,5,6-тетрагідро-7Н-азепін одержано алкілуванням капролактаму диметилсульфатом. 3-(41-Бромфеніл)-6,7,8,9-тетрагідро-5H-[1,2,4]триазоло[4,3-а]азепін одержано конденсацією 2-метокси-3,4,5,6-тетрагідро-7Н-азепіну з гідразидом пара-бромбензойної кислоти та подальшою циклізацією проміжного продукту. Спектри ПМР були зареєстровані на спектрометрі Bruker VXR-300, робоча частота - 299,945 МГц, внутрішній стандарт ТМС. Контроль за чистотою синтезованих сполук здійснювався за допомогою TШX на пластинках Silufol UV-254 в системі хлорофрорм - метанол $9: 1$.

Висновки. Синтезовані нові хімічні речовини - похідні 1,4-діарил-5,6,7,8-тетрагідро-2,2а,8а-триазациклопента [cd]азулену. Вивчена протиракова активність одержаних сполук на 60 лініях пухлинних клітин в Національному інституті раку США. Ідентифріковані високоактивні сполуки, які проявили високий рівень протипухлинної активності.

Ключові слова: 1,4-діарил-5,6,7,8-тетрагідро-2,2а,8а-триазациклопента[сd]азулени; протипухлинна активність 


\section{С. А. Демченко, Ю. А. Федченкова, Л. С. Бобкова, Л. П. Артемчук, А. М. Демченко}

Синтез и изучение противоопухолевой активности производных 1,4-диарил-5,6,7,8тетрагидро-2,2a,8а-триазациклопента[со]азуленов

Цель работы - синтезировать, доказать структурное строение и провести изучение противоопухолевой активности производных 1,4-диарил-5,6,7,8-тетрагидро-2,2А, 8а-триазациклопента[сс]азулена.

Результаты и их обсуждение. Для определения противоопухолевой активности 1-фенил-4-арил5,6,7,8-тетрагидро-2,2a, 8а-триазациклопента [cd] азулена 7a-g и 1-(41-бромфенил)-4-арил-5,6,7,8-тетрагидро2,2a,8a-триазациклопента[сd]азулена $7 \mathrm{~h}-\mathrm{k}$ было проведено исследование in vitro на 60 линиях раковых клеток (лейкемии, легких, толстого кишечника, ЦНС, меланомы, яичников, почек, простаты, молочной железы) при воздействии вещества в концентрации $10^{-5}$ моль/л по стандартной процедуре оценки митотической активности новых потенциальных биологически активных соединений методом фрлуоресцентной окраски (краситель - сульфоородамин Б), выполненных в Национальном институте рака США (National Cancer Institute of Health, USA) в рамках Development Therapeutic Program.

Экспериментальная часть. 2-метокси-3,4,5,6-тетрагидро-7Н-азепин получено алкилированием капролактама диметилсульфатом. 3-(41-бромфенил)-6,7,8,9-тетрагидро-5H-[1,2,4]триазоло[4,3-а]азепин получено конденсацией 2-метокси-3,4,5,6-тетрагидро-7Н-азепин с гидразидом парабромбензойной кислоты и последующей циклизацией промежуточного продукта. Спектры ПМР были зарегистрированы на спектрометре Bruker VXR-300, рабочая частота - 299,945 МГц, внутренний стандарт TMC. Контроль за чистотой синтезированных соединений осуществлялся с помощью TCX на пластинках Silufol UV-254 в системе хлороформ - метанол $9: 1$.

Выводы. Синтезированы новые химические соединения - производные 1,4-диарил-5,6,7,8-тетрагидро2,2а,8а-триазациклопента[cd]азулена. Изучена противораковая активность полученных соединений на 60 линиях опухолевых клеток в Национальном институте рака США. Идентифицированы высокоактивные соединения, которые проявили высокий уровень противоопухолевой активности.

Ключевые слова: 1,4-диарил-5,6,7,8-тетрагидро-2,2а,8а-триазациклопента[сd]азулены; противоопухолевая активность

For today more than 50 antitumor medicines active at different forms of malignant formations are applied for the treatment of a tumoral disease and achievement of the palliative effect, which leads to tumor reduction and consequently to clinical remission. Antineoplastic drugs with different mechanisms of action which are used in the treatment regimens are known. At the same time, the pronounced clinical effect is from $20 \%$ to $80 \%$, in some cases remission is up to 2 years, and more than $10 \%$ of patients have remission more than 3 years. Cyclophosphamide, methotrexate, vincristine, adriablastin have had a wide application [1-3]. Methotrexate inhibits the cellular mitosis, slows down the growth of malignant formations and is more active in relation to cells, which rapidly grow. Adriamycin is the only cytostatic agent exhibiting an insignificant activity in relation to hepatocellular carcinomas (the curative effect is 3-70\%, mostly $36.5 \%$ ). The mechanism of drug multiresistance impedes the use of cytostatic medicines.

The medicines mentioned have the necessary medicinal properties, but show considerable side effects of blood formation (leukopenia, anemia, thrombocytopenia), CNS (feeling of tiredness, dizziness, headache, aphasia, drowsiness, convulsions), reproductive system (osteogenesis and spermatogenesis disorders, oligospermatism, menstrual disorders, decreased libido, impotence), urinary system (hematuria, cystitis, severe renal dysfunction), allergic and dermatological reactions and other side effects.

Some triazole derivatives demonstrate the antioplastic action - these are Letrozole, Anastrozole and Vorozole [4].
The medicine Letrozole (Femara) - 4,4 ' - ( 1 H1,2,4-triazol-1-yl)-methylene) dibenzonitrile used as an antineoplastic hormonal drug and antagonist of hormones in malignant formations of a mammary gland is known [5-6].

Anastrozole shows the activity against estrogendependent breast tumors in women $[7,8]$. It is a selective non-steroid inhibitor of the enzyme aromatase, which leads to a decrease in the estradiol levels in peripheral tissues. It is known that breast tumor diseases in the world are $22.9 \%$ of the total amount of oncological diseases (Fig. 1) [9].

When taking Anastrozole and Letrozole anemia, thrombophlebitis and leukopenia can progress, and these indications are the reason for drug withdrawal.

\section{Results and discussion}

Increase in efficiency of chemotherapy of a tumoral disease, first of all, is connected with creation of new, effective antineoplastic medicines.

The derivatives of 1-phenyl-4-aryl-5,6,7,8-tetrahydro-2,2a,8a-triazacyclopenta[ $[c d]$ azulenes 7a-g and 1-( $4^{1}$-bromophenyl)-4-aryl-5,6,7,8-tetrahydro2,2a,8a-triazacyclopenta[ $[c d]$ azulenes $\mathbf{7 h}-\mathbf{k}$ showing the antineoplastic activity were synthesized.

The derivatives of 1-phenyl-4-aryl-5,6,7, 8-tetrahydro-2,2a,8a-triazacyclopenta[cd]azulenes 7a-g and 1-(41-bromophenyl)-4-aryl-5, 6,7,8-tetrahydro-2,2a,8atriazacyclopenta[ $[c d]$ azulenes $\mathbf{7 h}$-k were obtained with high yields when using the known synthetic approaches in several stages by the following Scheme (Fig. 2).

To determine the antineoplastic activity of 1-phenyl-4-aryl-5,6,7,8-tetrahydro-2,2a,8a-triaza- 


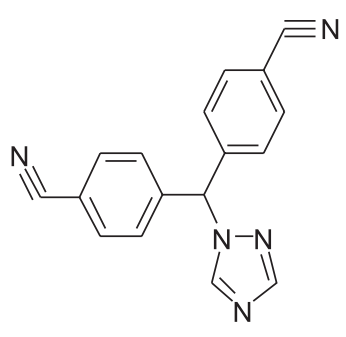

Letrozole

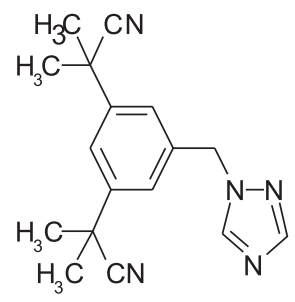

Anastrozol<smiles>Cn1nnc2ccc(C(c3ccc(Cl)cc3)n3cncn3)cc21</smiles>

Vorozole

Fig. 1. The structural formula for Letrozole, Anastrozole and Vorozole

cyclopenta[cd]azulenes 7a-g and 1-(41-bromophenyl)4-aryl-5,6,7,8-tetra-hydro-2,2a,8a-triazacyclopenta $[c d]$ azulenes $\mathbf{7 h}-\mathbf{k}$ the study in vitro was carried out on 60 lines of cancer cells (leukemia, nonsmall cell lung cancer, colon cancer, CNS cancer, melanoma, ovarian cancer, renal cancer, prostate cancer and breast cancer) under the effect of the substance in the concentration of 10-5 mol/l according to the standard procedure of the mitotic activity assessment of the new potential bioactive compounds by the fluorescent coloring method (sulphorhodamine B as a dye) performed in the US National Institute of cancer within the Development Therapeutic Program [10]. The re- sult of the studies conducted was expressed as a percentage of the cancer cell growth compared to the control - 5-fluorouracil. Tab. 1 shows the efficiency of compounds in inhibition of the cancer cell growth compared to the control.

The determination is performed by a highly sensitive fluorometric method, assessing quantitatively the intensity of fluorescent radiation color (sulphorhodamine B as a dye) in 48 hours of cell radiation with the compound tested. The result of the studies conducted was expressed as a percentage of the cancer cell growth compared to the control. The system of selection and study of compounds with the potential

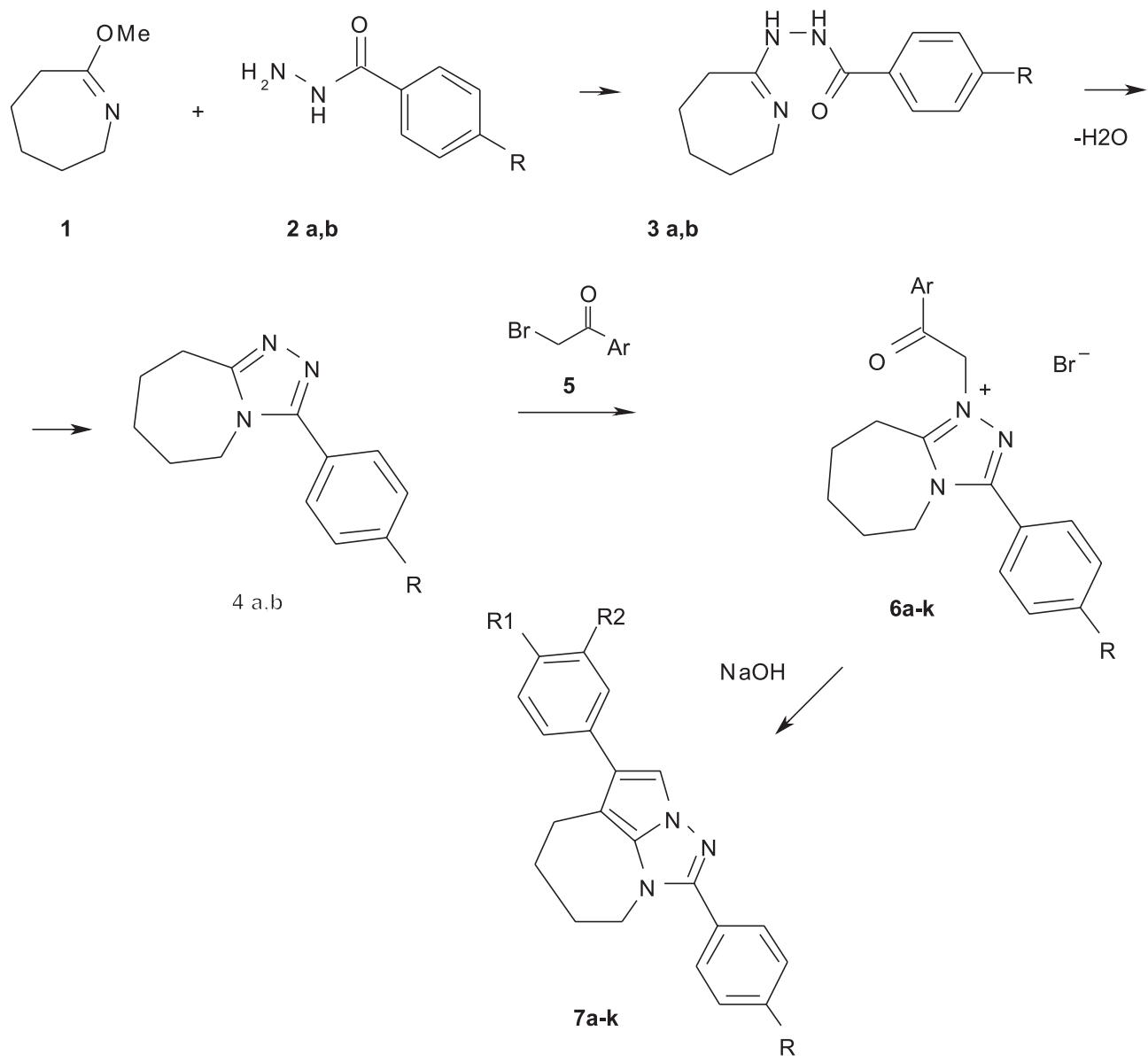

where 2-4 a) $R=H$, b) $R=B r$. 5-7 a): $R, R_{1}, R_{2}=H$, b) $R, R_{2}=H, R_{1}=C_{3}$; c) $R, R_{2}=H, R_{1}=O_{C H}$; d) $R, R_{2}=H, R_{1}=O C_{2} H_{5}$; e) $\mathrm{R}=\mathrm{H}, \mathrm{R}_{1} \mathrm{R}_{2}=-\mathrm{OCH}_{2} \mathrm{CH}_{2} \mathrm{O}-$; f) $\mathrm{R}, \mathrm{R}_{2}=\mathrm{H}, \mathrm{R}_{1}=\mathrm{Cl}$; g) $\mathrm{R}, \mathrm{R}_{2}=\mathrm{H}, \mathrm{R}_{1}=\mathrm{Br}$; h) $\mathrm{R}=\mathrm{Br}, \mathrm{R}_{2}=\mathrm{H}, \mathrm{R}_{1}=\mathrm{CH}_{3}$; i) $\mathrm{R}=\mathrm{Br}, \mathrm{R}_{2}=\mathrm{H}, \mathrm{R}_{1}=\mathrm{OCHF}_{2}$; j) $\left.\mathrm{R}=\mathrm{Br}, \mathrm{R}_{1}, \mathrm{R}_{2}=\mathrm{OCH}_{3} ; \mathbf{k}\right) \mathrm{R}=\mathrm{Br}, \mathrm{R}_{1} \mathrm{R}_{2}=-\mathrm{OCH}_{2} \mathrm{CH}_{2} \mathrm{O}$.

Fig. 2. The synthesis of 1,4-diaryl-5,6,7,8-tetrahydro-2,2a,8a-triazacyclopenta[cd]azulenes 7 a-k 
antineoplastic activity in vitro is based on the determination of percentage of the cancer cell growth (PG) under the effect of the compound tested. In the experimental conditions, the compounds studied in the concentration of $10-5 \mathrm{~mol} / \mathrm{l}$ found the ability to inhibit the growth of cancer cells covering almost the entire spectrum of human cancer (Tab. 1).

According to Tab. 1 compounds 7 b-e with electron-donor substitutes in position 4 of the heterocyclic system in relation to cells of leukemia, non-small cell lung cancer, colon cancer, CNS cancer, melanoma, ovarian cancer, renal cancer, prostate cancer and breast cancer revealed the highest antineoplastic activity than the reference drug - 5-fluorouracil.

Compounds with electron-withdrawing substitutes $\mathbf{7 f}$, $\mathbf{g}$ showed the activity at the level of the reference drug.

Thus, all compounds 7a-g inhibited the growth of cancer cells of CCRF-CEM, HL-60 (TB), K-562, MOLT-4, RPMI-8226 and SR leukemia more than the reference by $11.09-94.60 \%$. In relation to CCRF-CEM cells the data of compounds $\mathbf{7 c}$ and $\mathbf{7 d}$ were $-0.35 \%$ and $-6.01 \%$, respectively, i.e. these compounds not only stopped the growth and division of cells, but also destroyed them.

Compounds $\mathbf{7 c}$ and $\mathbf{7 d}$ stopped the growth and division of COLO 205 cells of colon cancer, and destroyed them by $-47.03 \%$ and $-85.81 \%$, respectively. It should be noted that the same compounds were especially active in relation to cancer cells of MCF7, HS 578T, VT-549 and MDA-MB-468 breast cancer with the values of $-12.82 \%,-15.55 \%,-0.58 \%$ and $-9.61 \%$, respectively.

Compound $\mathbf{7 h}$ exceeded the reference drug on 19 lines of cancer cells, $\mathbf{7 i}$ - on 18 lines, $\mathbf{7 j}$ - on 52 lines and $\mathbf{7 k}$ - on 47 lines among 60 lines studied.

Compound $\mathbf{7 h}$ was effective against HL-60 (TB) leukemia cells (exceeding the action of 5 -fluorouracil by $15.58 \%$ ), UACC- 257 melanoma (exceeding the action of 5-fluorouracil by $18.23 \%$ ), PC-3 prostate cancer (exceeding the action of 5-fluorouracil by $11.71 \%$ ).

Compound $7 \mathbf{i}$ was effective against RPMI-8226 leukemia cells (exceeding the action of 5 -fluorouracil by $23.32 \%$ ), EKVX non-small cell lung cancer (exceeding the action of 5 -fluorouracil by $11.96 \%$ ), NT-29 colon cancer (exceeding the action of 5 -fluorouracil by $25.59 \%$ ), TK-10 renal cancer (exceeding the action of 5-fluorouracil by $41.94 \%$ ).

Compound $\mathbf{7 j}$ was effective against CCRF-CEM, HL60 (TB) leukemia cells, MOLT-4 indicators were $-24.52 \%$; $-13.14 \%$; $-5.16 \%$, respectively, i.e. this compound not only stopped the growth and division of cells, but also destroyed them. The compound destroyed HOP-92 non-small cell lung cancer - $25.68 \%$; OVCAR-3 ovarian cancer $-13.80 \%$ and UO-31 renal cancer $-29.09 \%$. This compound showed the activity in relation to K-562 leukemia cells (exceeding the ac- tion of 5-fluorouracil by $93.25 \%$ ), HCT-116 colon cancer (exceeding the action of 5-fluorouracil by $96.20 \%$ ), PC-3 prostate cancer (exceeding the action of 5 -fluorouracil by $93.14 \%$ ), VT-549, T-47D breast cancer (exceeding the action of 5 -fluorouracil by $79.97 \%$ and $81.62 \%$, respectively).

Compound $\mathbf{7 k}$ was effective against CCRF-CEM, RPMI-8226 leukemia cells (exceeding the action of 5 -fluorouracil by $95.82 \%$ and $83.51 \%$, respectively), HOP-92 non-small cell lung cancer (exceeding the action of 5 -fluorouracil by $40.88 \%$ ), HCT-116 colon cancer (exceeding the action of 5-fluorouracil by $16.04 \%$ ), SF-539 CNS cancer (exceeding the action of 5-fluorouracil by $17.93 \%$ ), LOX IMVI, M14, SK-MEL-2 melanoma (exceeding the action of 5-fluorouracil by $14.28 \%$; $13.27 \%$; and $20.68 \%$, respectively), OVCAR-5, OVCAR-8 ovarian cancer (exceeding the action of 5-fluorouracil by $17.73 \%$ and $18.05 \%$ ), PC-3 prostate cancer (exceeding the action of 5-fluorouracil by $81.12 \%$ ).

At the second stage of our studies, or the in-depth screening in vitro, the compounds were tested in five concentrations in 10 -fold dilution $(100 \mu \mathrm{m}, 10 \mu \mathrm{m}$, $1 \mu \mathrm{m}, 0.1 \mu \mathrm{m}$ and $0.01 \mu \mathrm{m}$ ) on the lines of human cancer cells listed. As a result of the experiment three dose-dependent parameters, namely GI50 - the concentration of the compound causing inhibition of $50 \%$ cell line growth; TGI - the concentration creating complete inhibition of the cell growth; $\mathrm{LC}_{50}$ - the concentration causing death of $50 \%$ of tumor cells, were calculated. $\mathrm{GI}_{50}$ is interpreted as the effective level of inhibition, TGI is the cytostatic effect, while $\mathrm{LC}_{50}$ is the lethal concentration causing the cytotoxic action. If logarithmic values of the parameters studied $\left(\operatorname{lgGI}_{50}\right.$, $\operatorname{lgTGI}$ and $\operatorname{lgLC} \mathrm{C}_{50}$ ) are less than -4.00 , then the compound is considered to be active [11-13].

According to the results of the screening (Tab. 2), the compounds tested revealed the considerable level of the anticarcinogenic activity. Compound $\mathbf{7 b}$ showed the significant level of the anticarcinogenic activity in relation to HOP-62 $(\operatorname{lgGI} 50=-5.76$; $\lg \mathrm{TGI}=-5.42$; $\operatorname{lgLC50}=-5.08$ ) non-small cell lung cancer; SNB-75 CNS cancer $\left(\operatorname{lgGI}_{50}=-5.68 ; \operatorname{lgTGI}=-5.32 ; \operatorname{lgLC} \mathrm{L}_{50}=-4.79\right)$ and U251 $\left(\operatorname{lgGI}_{50}=-5.57 ; \operatorname{lgTGI}=-5.07 ; \operatorname{lgLC}_{50}=-4.16\right)$; OVCAR-3 ovarian cancer $\left(\operatorname{lgGI}_{50}=-5.61 ; \operatorname{lgTGI}=-5.27\right.$; $\left.\operatorname{lgLC}_{50}=-4.10\right)$ and SK-OV-3 $\left(\operatorname{lgGI}_{50}=-5.67 ; \operatorname{lgTGI}=-5.28\right.$; $\left.\operatorname{lgLC} C_{50}=-4.27\right)$.

Compound $\mathbf{7 c}$ had the anticarcinogenic activity in relation to MOLT-4 $\left(\operatorname{lgGI}_{50}=-5.75 ; \operatorname{lgTGI}=-5.39\right.$; $\operatorname{lgLC}{ }_{50}=-5.03$ ) leukemia; HOP-92 non-small cell lung cancer $\left(\operatorname{lgGI}_{50}=-5.91 ; \operatorname{lgTGI}=-5.38 ; \operatorname{lgLC} C_{50}=-4.27\right)$ and NCI-H522 (lgGI 50 - -5.72; $\left.\operatorname{lgTGI}=-5.26 ; \operatorname{lgLC}_{50}=-4.45\right)$; COLO 205 colon cancer $(\operatorname{lgGI} 50=-5.65 ; \operatorname{lgTGI}=-5.30$; $\left.\operatorname{lgLC}_{50}=-4.87\right), \mathrm{HCC} 2998\left(\operatorname{lgGI}_{50}=-5.42 ; \lg \mathrm{TGI}=-4.83\right.$; $\left.\operatorname{lgLC}_{50}=-4.19\right)$ та НCT-116 $(\operatorname{lgGI})_{50}=-5.60 ; \operatorname{lgTGI}=-4.93$; $\operatorname{lgLC}_{50}=-4.07$ ); SF-539 CNS cancer $\left(\operatorname{lgGI}_{50}=-5.43\right.$; $\left.\operatorname{lgTGI}=-4.80 ; \operatorname{lgLC}{ }_{50}=-4.20\right)$ and $\mathrm{U} 251\left(\operatorname{lgGI}_{50}=-5.56\right.$; $\operatorname{lgTGI}=-4.86 ; \operatorname{lgLC} C_{50}=-4.00$ ); LOX IMVI melanoma 
Table 1

The anti-tumor activity of 1,4-diaryl-5,6,7,8-tetrahydro-2,2a,8a-triazacyclopenta[cd]azulenes $\mathbf{7} \mathbf{~ h - k}$ in vitro on the lines of cancer cells under the action of substances in the concentration of $10^{-5} \mathrm{~mol} / \mathrm{L}$

\begin{tabular}{|c|c|c|c|c|c|c|c|c|c|c|c|c|}
\hline \multicolumn{2}{|c|}{ The lines of cancer cells } & $7 a$ & $7 b$ & $7 c$ & 7d & $7 e$ & $7 f$ & $7 \mathrm{~g}$ & $7 \mathrm{~h}$ & $7 \mathbf{i}$ & $7 \mathbf{j}$ & $7 k$ \\
\hline 1 & 2 & 3 & 4 & 5 & 6 & 7 & 8 & 9 & 10 & 11 & 12 & 13 \\
\hline \multirow{6}{*}{ Leukemia } & CCRF-CEM & 36.45 & 11.08 & -0.36 & -6.01 & 13.38 & 79.98 & 42.33 & 88.79 & 117.33 & -24.52 & 4.18 \\
\hline & $\mathrm{HL}-60$ (TB) & 48.12 & -1.56 & -20.72 & 45.27 & 56.24 & 93.93 & 88.18 & 84.32 & 99.56 & -13.14 & 96.87 \\
\hline & K-562 & 32.89 & 10.27 & 7.22 & 19.60 & 21.60 & 82.05 & 79.43 & 105.17 & 91.79 & 6.75 & 88.90 \\
\hline & MOLT-4 & 51.99 & 21.17 & 3.47 & 33.73 & 15.08 & 76.61 & 62.86 & 93.08 & 100.52 & -5.16 & 87.09 \\
\hline & RPMI-8226 & 30.83 & 17.18 & 15.20 & 25.07 & 21.68 & 94.56 & 78.04 & 101.07 & 76.68 & 7.36 & 16.49 \\
\hline & SR & 65.69 & 26.07 & 5.40 & 52.47 & 47.70 & 78.96 & 88.91 & 93.43 & 108.10 & 9.36 & 90.33 \\
\hline \multirow{9}{*}{$\begin{array}{l}\text { Non-Small } \\
\text { Cell Lung } \\
\text { Cancer }\end{array}$} & A549/ATCC & 71.48 & 35.01 & 13.14 & 90.39 & 25.00 & 88.58 & 82.41 & 88.39 & 90.95 & 46.49 & 90.80 \\
\hline & EKVX & 52.57 & 14.35 & - & - & 43.06 & - & - & 104.42 & 88.04 & - & - \\
\hline & HOP-62 & 70.51 & 40.83 & 7.40 & 103.6 & 39.85 & 108.7 & 99.80 & 119.31 & 107.70 & 63.91 & 96.19 \\
\hline & HOP-92 & - & - & -4.13 & 43.08 & 20.16 & 95.15 & 79.42 & 78.16 & - & -25.68 & 59.12 \\
\hline & $\mathrm{NCl}-\mathrm{H} 226$ & 88.55 & 34.02 & 21.07 & 100.3 & 43.91 & 102.5 & 85.72 & 95.58 & 103.72 & 78.87 & 96.71 \\
\hline & $\mathrm{NCl}-\mathrm{H} 23$ & 86.79 & 42.46 & 8.91 & 90.65 & 72.96 & 96.66 & 98.87 & 107.42 & 108.50 & 100.59 & 86.15 \\
\hline & $\mathrm{NCl}-\mathrm{H} 322 \mathrm{M}$ & 122.5 & 78.19 & 15.20 & 94.91 & 60.15 & 95.51 & 117.7 & 110.08 & 99.09 & 25.38 & 115.44 \\
\hline & $\mathrm{NCl}-\mathrm{H} 460$ & - & 27.87 & - & - & 30.64 & 105.4 & 94.93 & 103.17 & 102.09 & - & - \\
\hline & $\mathrm{NCl}-\mathrm{H} 522$ & - & - & 35.98 & 83.37 & 69.18 & 83.64 & 97.50 & 93.01 & - & 47.47 & 75.34 \\
\hline \multirow{7}{*}{ Colon Cancer } & COLO 205 & 56.98 & -47.03 & -85.81 & 98.44 & 26.94 & 104.1 & 103.3 & 118.12 & 121.10 & 50.47 & 101.44 \\
\hline & HCC2998 & 88.70 & - & 21.37 & 98.45 & 46.25 & 106.1 & 110.4 & 106.79 & 112.04 & 103.34 & 88.64 \\
\hline & HCT-116 & 35.69 & 1.59 & -1.47 & 53.96 & 11.09 & 89.81 & 77.69 & 113.29 & 95.52 & 3.80 & 83.96 \\
\hline & HCT-15 & 101.5 & 77.51 & 39.17 & 104.0 & 84.59 & 94.09 & 97.42 & 110.44 & 111.93 & 54.63 & 91.42 \\
\hline & HT-29 & 43.88 & 11.54 & 6.95 & 110.4 & 30.18 & 98.02 & 104.1 & 109.14 & 74.41 & 31.50 & 92.39 \\
\hline & KM12 & 57.61 & 20.71 & 14.73 & 69.85 & 35.11 & 99.02 & 74.82 & 111.46 & 103.74 & 19.79 & 93.21 \\
\hline & SW-620 & - & 21.23 & - & - & 34.70 & 111.3 & 105.8 & 106.31 & 104.66 & - & - \\
\hline \multirow{6}{*}{ CNS Cancer } & SF-268 & 87.21 & 47.78 & 23.10 & 85.34 & 50.78 & 86.45 & 98.63 & 103.48 & 103.02 & 38.18 & 96.98 \\
\hline & SF-295 & - & 30.01 & - & - & 35.47 & - & - & 105.47 & 137.23 & - & - \\
\hline & SF-539 & 88.32 & 63.68 & 11.63 & 96.28 & 56.30 & 95.87 & 108.2 & 116.41 & 111.67 & 71.95 & 82.07 \\
\hline & SNB-19 & 73.33 & 38.36 & - & - & 52.79 & - & - & 100.11 & 98.61 & - & - \\
\hline & SNB-75 & - & - & 28.71 & 88.33 & 54.03 & 87.87 & 90.65 & 106.95 & - & 71.63 & 94.01 \\
\hline & U251 & 41.17 & 26.17 & 10.26 & 92.75 & 8.45 & 89.97 & 84.64 & 86.94 & 93.79 & 23.48 & 88.11 \\
\hline \multirow{9}{*}{ Melanoma } & LOX IMVI & 77.74 & 22.83 & 9.87 & 84.26 & 33.49 & 99.45 & 90.61 & 105.67 & 100.15 & 96.36 & 85.72 \\
\hline & MALME-3M & 86.46 & 0.27 & -11.78 & 86.23 & 16.44 & - & - & 98.55 & 85.42 & 36.07 & 87.00 \\
\hline & M14 & 73.57 & 30.97 & 13.72 & 91.75 & 37.57 & 105.4 & 90.55 & 106.55 & 103.36 & 35.21 & 86.73 \\
\hline & MDA-MB-435 & 80.37 & 22.74 & 10.95 & 96.74 & 30.82 & 101.1 & 108.3 & 112.99 & 113.54 & 16.28 & 104.79 \\
\hline & SK-MEL-2 & - & - & 0.56 & 98.76 & - & 101.2 & 112.2 & - & - & 69.14 & 79.32 \\
\hline & SK-MEL-28 & 74.73 & 28.90 & 43.24 & 102.2 & 63.74 & 102.3 & 108.1 & 113.92 & 114.18 & 97.33 & 105.65 \\
\hline & SK-MEL-5 & 81.81 & 6.10 & 1.44 & 98.92 & 26.83 & 97.28 & 88.50 & 97.05 & 97.53 & 52.00 & 96.06 \\
\hline & UACC-257 & 87.91 & 24.36 & 18.97 & 103.6 & 0.71 & 99.48 & 105.1 & 81.77 & 101.25 & 58.15 & 96.22 \\
\hline & UACC-62 & 81.36 & 52.61 & 35.89 & 93.40 & 49.53 & 93.01 & 93.38 & 106.04 & 94.77 & 74.07 & 87.87 \\
\hline \multirow{7}{*}{$\begin{array}{l}\text { Ovarian } \\
\text { cancer }\end{array}$} & IGROV1 & 74.21 & 15.84 & 25.81 & 98.63 & 56.48 & 94.87 & 99.39 & 114.56 & 101.51 & 31.00 & 95.23 \\
\hline & OVCAR-3 & 59.96 & -23.00 & -17.59 & 53.10 & 33.80 & 103.8 & 92.40 & 117.55 & 109.40 & -13.80 & 95.53 \\
\hline & OVCAR-4 & - & - & 31.60 & 97.84 & 65.81 & 99.75 & 92.22 & 97.88 & 108.87 & 83.18 & 99.63 \\
\hline & OVCAR-5 & 90.97 & 74.56 & 36.28 & 86.23 & 99.34 & 88.23 & 87.89 & 99.05 & 106.59 & 39.08 & 82.27 \\
\hline & OVCAR-8 & 54.57 & 29.22 & 14.31 & 78.65 & 9.22 & 82.38 & 78.95 & 91.69 & 109.86 & 44.38 & 81.95 \\
\hline & $\mathrm{NCl} / \mathrm{ADR}-\mathrm{RES}$ & 100.9 & 92.18 & 78.66 & 101.2 & 92.59 & 106.4 & 102.84 & 107.55 & 104.57 & 103.61 & 96.83 \\
\hline & SK-OV-3 & - & - & 27.80 & 99.22 & 82.59 & 96.63 & 102.75 & 120.71 & 106.93 & 83.57 & 91.88 \\
\hline
\end{tabular}


Continuation of Table 1

\begin{tabular}{|c|c|c|c|c|c|c|c|c|c|c|c|c|}
\hline 1 & 2 & 3 & 4 & 5 & 6 & 7 & 8 & 9 & 10 & 11 & 12 & 13 \\
\hline \multirow{8}{*}{ Renal Cancer } & $786-0$ & 82.60 & 28.40 & 13.82 & 94.03 & 68.63 & 96.04 & 92.30 & 101.16 & 98.95 & 50.80 & 96.52 \\
\hline & A498 & - & 50.13 & 28.35 & 78.77 & 73.45 & 108.0 & 84.39 & 105.70 & 106.36 & 59.60 & 116.27 \\
\hline & $\mathrm{ACHN}$ & 77.06 & 16.73 & 5.60 & 80.57 & 55.50 & 94.97 & 88.04 & 113.11 & 109.62 & 25.54 & 87.88 \\
\hline & CAKI-1 & 112.7 & 66.55 & 70.01 & 92.04 & 81.67 & 97.62 & 95.19 & 99.32 & 107.78 & 66.24 & 97.72 \\
\hline & RXF 393 & 96.22 & 45.79 & 23.74 & 110.2 & 58.55 & 114.8 & 103.6 & 101.24 & 116.50 & 82.46 & 101.82 \\
\hline & SN12C & 75.20 & 48.84 & 15.18 & 91.08 & 24.67 & 90.33 & 86.18 & 101.54 & 100.44 & 59.84 & 83.41 \\
\hline & TK-10 & 38.10 & 11.66 & 30.75 & 98.02 & 73.20 & 100.2 & 105.6 & 104.17 & 58.06 & 73.04 & 98.29 \\
\hline & UO-31 & 81.52 & 50.95 & 11.34 & 82.47 & 77.64 & 79.40 & 86.72 & 96.54 & 84.67 & -29.09 & 90.06 \\
\hline \multirow{2}{*}{$\begin{array}{l}\text { Prostate } \\
\text { cancer }\end{array}$} & $P C-3$ & 86.35 & 22.90 & 9.47 & 19.28 & 9.61 & 83.39 & 72.38 & 88.29 & - & 6.86 & 18.88 \\
\hline & DU-145 & 81.38 & 33.92 & 19.78 & 74.58 & 41.00 & 108.6 & 93.58 & 111.97 & 101.46 & 30.73 & 101.07 \\
\hline \multirow{6}{*}{ Breast cancer } & MCF7 & 21.85 & -12.82 & 13.28 & 94.86 & 37.09 & 86.98 & 80.80 & 96.23 & 95.68 & 67.25 & 94.64 \\
\hline & $\begin{array}{c}\text { MDA- } \\
\text { MB-231/ATCC } \\
\end{array}$ & 79.64 & 52.47 & 15.46 & 95.53 & 68.38 & 105.3 & 88.40 & 106.44 & 109.93 & 89.28 & 97.81 \\
\hline & HS 578T & - & -15.55 & 27.76 & 86.95 & 27.36 & 92.79 & 82.80 & 113.12 & 110.88 & 49.98 & 103.38 \\
\hline & BT-549 & - & - & -0.58 & 73.95 & 51.29 & 99.51 & 88.66 & - & - & 20.03 & 73.76 \\
\hline & T47D & - & - & 1.97 & 66.14 & 58.32 & 82.51 & 73.93 & 114.50 & 88.12 & 18.38 & 76.04 \\
\hline & MDA-MB-468 & 45.83 & 3.71 & -9.61 & 89.38 & 18.61 & 113.4 & 83.85 & 102.12 & 108.74 & 49.43 & 92.91 \\
\hline
\end{tabular}

$\left(\operatorname{lgGI}_{50}=-5.60 ; \lg \mathrm{TGI}=-5.12 ; \operatorname{lgLC} \mathrm{C}_{50}=-4.54\right)$, MALME-3M $\left(\operatorname{lgGI}{ }_{50}=-5.73 ; \lg T G I=-5.38 ; \operatorname{lgLC}_{50}=-5.03\right)$, SK-MEL-2 $\left(\operatorname{lgGI}_{50}=-5.61 ; \lg \mathrm{TGI}=-5.27 ; \operatorname{lgLC}_{50}=-4.57\right)$, SK-MEL-28 $\left(\operatorname{lgGI}{ }_{50}=-5.48 ; \lg T G I=-4.84 ; \operatorname{lgLC} C_{50}=-4.22\right)$, SK-MEL-5 $\left(\operatorname{lgGI} \mathrm{I}_{50}=-5.77 ; \lg \mathrm{TGI}=-5.48 ; \operatorname{lgLC} \mathrm{C}_{50}=-5.19\right)$, UACC -62 $\left(\operatorname{lgGI}{ }_{50}=-5.76 ; \lg \mathrm{TGI}=-5.40 ; \operatorname{lgLC}_{50}=-5.04\right) ; \mathrm{RXF} 393$ renal cancer $\left(\lg \mathrm{GI}_{50}=-5.65 ; \lg \mathrm{TGI}=-5.13 ; \operatorname{lgLC_{50}}=-4.44\right)$ and UO-31 $\left(\operatorname{lgGI}_{50}=-5.55\right.$; $\left.\operatorname{lgTGI}=-4.95 ; \operatorname{lgLC}_{50}=-4.14\right)$; MDA-MB-231/ATCC breast cancer $\left(\operatorname{lgG} \mathrm{I}_{50}=-5.68\right.$; $\lg \mathrm{TGI}=-5.30 ; \operatorname{lgLC} \mathrm{C}_{50}=-4.39$ ).

Compound $\mathbf{7 e}$ had the anticarcinogenic activity in relation to MOLT-4 $\left(\operatorname{lgG} \mathrm{I}_{50}=-5.75\right.$; $\lg \mathrm{TGI}=-5.32$; $\operatorname{lgLC}_{50}=-4.26$ ) leukemia; HOP-62 non-small cell lung cancer $\left(\operatorname{lgGI} \mathrm{I}_{50}=-5.55 ; \lg \mathrm{TGI}=-4.92 ; \operatorname{lgLC} \mathrm{C}_{50}=-4.19\right)$, NCI-H460 $\left(\operatorname{lgGI}_{50}=-5.56 ; \lg \mathrm{TGI}=-4.97 ; \operatorname{lgLC}_{50}=-4.25\right)$ and NCI-H522 lgGI $\left._{50}=-5.54 ; \operatorname{lgTGI}=-4.91 ; \operatorname{lgLC}_{50}=-4.19\right)$; COLO 205 colon cancer $\left(\operatorname{lgGI}_{50}=-5.70 ; \lg \mathrm{TGI}=-5.33\right.$; $\left.\operatorname{lgLC}_{50}=-4.81\right), \mathrm{HCC} 2998\left(\operatorname{lgGI}{ }_{50}=-5.47 ; \operatorname{lgTGI}=-4.79 ;\right.$ $\left.\operatorname{lgLC}_{50}=-4.15\right), \mathrm{HCT}-116\left(\operatorname{lgGI}{ }_{50}=-5.61 ; \lg \mathrm{TGI}=-4.98\right.$; $\left.\operatorname{lgLC}_{50}=-4.36\right), \mathrm{KM} 12\left(\operatorname{lgGI} \mathrm{I}_{50}=-5.49 ; \lg \mathrm{TGI}=-4.91\right.$; $\left.\operatorname{lgLC}_{50}=-4.39\right), \mathrm{SW}-620\left(\operatorname{lgGI} \mathrm{I}_{50}=-5.48 ; \operatorname{lgTGI}=-4.84\right.$; $\left.\operatorname{lgLC}_{50}=-4.38\right) ; \mathrm{SF}-295 \mathrm{CNS}$ cancer $\left(\operatorname{lgGI} \mathrm{I}_{50}=-5.65\right.$; $\left.\lg \mathrm{TGI}=-5.16 ; \operatorname{lgLC}_{50}=-4.40\right), \mathrm{SF}-539\left(\operatorname{lgGI}_{50}=-5.43\right.$; $\left.\operatorname{lgTGI}=-4.93 ; \operatorname{lgLC} \mathrm{C}_{50}=-4.35\right)$ and $\mathrm{U} 251\left(\operatorname{lgGI} \mathrm{I}_{50}=-5.70\right.$; $\left.\operatorname{lgTGI}=-4.86 ; \operatorname{lgLC}_{50}=-4.18\right) ;$ LOX IMVI melanoma $\left(\operatorname{lgGI}_{50}=-5.64 ; \lg \mathrm{TGI}=-4.94 ; \operatorname{lgLC} \mathrm{C}_{50}=-4.36\right)$, MALME-3M $\left(\operatorname{lgGI} \mathrm{I}_{50}=-5.71 ; \operatorname{lgTGI}=-5.25 ; \operatorname{lgLC} \mathrm{L}_{50}=-4.47\right), \mathrm{M} 14$ $\left(\operatorname{lgGI}_{50}=-5.48 ; \operatorname{lgTGI}=-4.89 ; \operatorname{lgLC}_{50}=-4.13\right)$, SK-MEL-28 $\left(\operatorname{lgGI}_{50}=-5.31 ; \operatorname{lgTGI}=-4.68 ; \operatorname{lgLC}_{50}=-4.10\right)$, SK-MEL-5 $\left(\operatorname{lgGI}{ }_{50}=-5.86 ; \operatorname{lgTGI}=-5.56 ; \operatorname{lgLC}_{50}=-5.26\right)$, UACC -62 $\left(\operatorname{lgGI}{ }_{50}=-5.75 ; \operatorname{lgTGI}=-5.27 ; \operatorname{lgLC}_{50}=-4.62\right) ;$ OVCAR-3 ovarian cancer $\left(\operatorname{lgGI}_{50}=-5.58\right.$; $\left.\lg \mathrm{TGI}=-5.01 ; \operatorname{lgLC_{50}}=-4.50\right)$; $786-0$ renal cancer $\left(\operatorname{lgGI} \mathrm{I}_{50}=-5.41 ; \lg \mathrm{TGI}=-4.80\right.$; $\left.\operatorname{lgLC}_{50}=-4.20\right)$ and RXF $393\left(\operatorname{lgGI}_{50}=-5.63 ; \lg \mathrm{TGI}=-5.02\right.$;
$\left.\operatorname{lgLC}{ }_{50}=-4.37\right) ;$ MDA-MB-231/ATCC breast cancer $\left(\operatorname{lgGI}{ }_{50}=-5.64 ; \operatorname{lgTGI}=-5.13 ; \operatorname{lgLC} C_{50}=-4.17\right) ; \mathrm{BT}-549$ $\left(\operatorname{lgGI} \mathrm{I}_{50}=-5.44 ; \lg \mathrm{TGI}=-5.02 ; \operatorname{lgLC}_{50}=-4.42\right)$ and MDAMB-468 $\left(\operatorname{lgGI}_{50}=\right.$-5.94; $\left.\lg \mathrm{TGI}=-5.07 ; \operatorname{lgLC} \mathrm{C}_{50}=-4.12\right)$.

Compound $7 \mathbf{j}$ was active in relation to COLO 205 cells of colon cancer $\left(\right.$ the $\operatorname{lgGI} \mathrm{I}_{50}$ value $=-5.32$, $\operatorname{lgTGI}=-4.76$ and $\operatorname{lgLC}_{50}=-4.27$ ) SK-MEL-5 melanoma $\left(\operatorname{lgGI}_{50}=-5.37\right.$, $\operatorname{lgTGI}=-4.76$ and $\operatorname{lgLC} \mathrm{C}_{50}=-4.25$ ) and RXF 393 renal cancer (the $\operatorname{lgGI} \mathrm{I}_{50}$ value $=-5.62, \lg \mathrm{TGI}=-5.08$, and $\operatorname{lgLC}_{50}=-4.21$ ).

Thus, the derivatives of 1-phenyl-4-aryl-5,6,7,8tetrahydro-2,2a,8a-triazacyclopenta [cd]azulenes and 1-(41'-bromophenyl)-4-aryl-5,6,7,8-tetrahydro2,2a,8a-triazacyclopenta [cd] azulene exhibit the antineoplastic activity in relation to a wide range of cancer cells and can become the basis for creating new effective anticancer agents.

\section{Experimental part}

2-Methoxy-3,4,5,6-tetrahydro-7H-azepine 1 was obtained by alkylation of caprolactam with dimethyl sulfate using the method [14]. 3-Phenyl or (41'-bromophenyl)-(6,7,8,9-tetrahydro-5H-[1,2,4] triazolo[4,3a] azepine $4 \mathrm{a}$,b was obtained by condensation of 2-methoxy-3,4,5,6-tetrahydro-7H-azepine 1 with 4-bromobenzoic acid hydrazide and subsequent cyclization of the intermediate product 3 by the method [15].

The ${ }^{1} \mathrm{H}-\mathrm{NMR}$-spectra were recorded on a Bruker VXR-300 spectrometer (Germany) with the working frequency of $299,945 \mathrm{MHz}$, in DMSO- $\mathrm{d}_{6}$ using tetramethylsilane (TMS) as an internal standard. The purity of the compounds synthesized was controlled by TLC on the Silufol UV-254 plates in the system of chloroform - methanol $(9: 1)$. 
Table 2

The results of the in-depth in vitro screening of compounds $\mathbf{7} \mathbf{b}, \mathbf{c}, \mathbf{e}, \mathbf{j}$ in the concentration gradient of $10^{-4}-10^{-8} \mathrm{M}$

\begin{tabular}{|c|c|c|c|c|c|c|c|c|c|c|c|c|c|}
\hline \multicolumn{2}{|c|}{ The lines of cancer cells } & \multirow{2}{*}{$\begin{array}{c}\begin{array}{c}7 \mathbf{7 b} \\
|\mathrm{gGG}|_{50}\end{array} \\
3\end{array}$} & \multirow{2}{*}{$\begin{array}{c}\begin{array}{c}7 \mathbf{b} \\
\text { lgTGl }\end{array} \\
4\end{array}$} & \multirow{2}{*}{\begin{tabular}{|c|}
$\begin{array}{c}7 \mathbf{b} \\
\lg \mathrm{C}_{50}\end{array}$ \\
5
\end{tabular}} & \multirow{2}{*}{\begin{tabular}{|c|}
$\begin{array}{c}7 c \\
\left.\operatorname{lgG|}\right|_{50}\end{array}$ \\
6
\end{tabular}} & \multirow{2}{*}{$\begin{array}{c}\begin{array}{c}7 c \\
|\mathrm{gTG}|\end{array} \\
7\end{array}$} & \multirow{2}{*}{$\frac{\begin{array}{c}7 c \\
\lg \mathrm{LC}_{50}\end{array}}{8}$} & \multirow{2}{*}{$\begin{array}{c}\begin{array}{c}7 e \\
\operatorname{lgGl}_{50}\end{array} \\
9\end{array}$} & \multirow{2}{*}{$\begin{array}{c}\begin{array}{c}7 e \\
\text { |gTG| }\end{array} \\
10\end{array}$} & \multirow{2}{*}{\begin{tabular}{|c|}
$\begin{array}{c}\mathbf{7 e} \\
\lg \mathrm{LC}_{50}\end{array}$ \\
11
\end{tabular}} & \multirow{2}{*}{$\begin{array}{c}\begin{array}{c}7 \mathbf{j} \\
\left.\operatorname{lgG|}\right|_{50}\end{array} \\
12\end{array}$} & \multirow{2}{*}{$\begin{array}{c}\begin{array}{c}7 \mathbf{j} \\
|\mathrm{gTG}|\end{array} \\
13\end{array}$} & \multirow{2}{*}{$\frac{\begin{array}{c}7 \mathbf{j} \\
\operatorname{lgL} C_{50}\end{array}}{14}$} \\
\hline 1 & 2 & & & & & & & & & & & & \\
\hline \multirow{6}{*}{ Leukemia } & CCRF-CEM & -5.55 & -4.00 & -4.00 & -6.07 & -5.50 & -4.00 & -5.88 & -5.26 & -4.00 & -5.62 & -5.16 & -4.00 \\
\hline & HL-60(TB) & - & - & - & -5.72 & -5.31 & -4.00 & -5.62 & -4.63 & -4.00 & -5.47 & -4.88 & -4.00 \\
\hline & K-562 & - & -4.00 & -4.00 & -5.94 & -5.07 & -4.00 & -6.03 & -4.99 & -4.00 & -5.43 & -4.00 & -4.00 \\
\hline & MOLT-4 & - & -4.00 & -4.00 & -5.75 & -5.39 & -5.03 & -5.75 & -5.32 & -4.26 & -5.54 & -5.08 & -4.00 \\
\hline & RPMI-8226 & -5.58 & -4.00 & -4.00 & -5.87 & -5.30 & -4.00 & -5.80 & -5.14 & -4.00 & -5.53 & -5.00 & -4.00 \\
\hline & SR & -4.00 & -4.00 & -4.00 & -5.85 & -5.17 & -4.00 & -5.82 & -5.20 & -4.00 & -5.48 & -4.09 & -4.00 \\
\hline \multirow{9}{*}{$\begin{array}{l}\text { Non-Small } \\
\text { Cell Lung } \\
\text { Cancer }\end{array}$} & A549/ATCC & -5.56 & - & -4.00 & -5.55 & -4.00 & -4.00 & -5.62 & -4.00 & -4.00 & -5.07 & -4.00 & -4.00 \\
\hline & EKVX & -5.42 & -4.00 & -4.00 & - & - & - & -5.63 & -4.00 & -4.00 & - & - & - \\
\hline & HOP-62 & -5.76 & -5.42 & -5.08 & -5.48 & -4.71 & -4.00 & -5.55 & -4.92 & -4.19 & -4.92 & -4.00 & -4.00 \\
\hline & HOP-92 & -5.79 & -5.25 & -4.00 & -5.91 & -5.38 & -4.27 & -5.63 & -5.17 & -4.00 & -5.75 & -5.22 & -4.00 \\
\hline & $\mathrm{NCl}-\mathrm{H} 226$ & -5.50 & -4.13 & -4.00 & -5.47 & -4.74 & -4.00 & -5.68 & -5.00 & -4.00 & -5.12 & -4.00 & -4.00 \\
\hline & $\mathrm{NCl}-\mathrm{H} 23$ & -5.30 & -4.00 & -4.00 & -5.59 & -5.04 & -4.00 & -5.47 & -4.00 & -4.00 & -5.10 & -4.00 & -4.00 \\
\hline & $\mathrm{NCl}-\mathrm{H} 322 \mathrm{M}$ & -5.42 & -4.00 & -4.00 & -5.58 & -5.11 & -4.00 & -5.45 & -4.49 & -4.00 & -4.82 & -4.00 & -4.00 \\
\hline & $\mathrm{NCl}-\mathrm{H} 460$ & -5.64 & - & -4.00 & -5.50 & -4.95 & -4.00 & -5.56 & -4.97 & -4.25 & -5.05 & -4.00 & -4.00 \\
\hline & $\mathrm{NCl}-\mathrm{H} 522$ & -5.48 & -4.99 & -4.00 & -5.72 & -5.26 & -4.45 & -5.54 & -4.91 & -4.19 & -5.48 & -4.49 & -4.00 \\
\hline \multirow{7}{*}{ Colon cancer } & COLO 205 & -5.29 & -4.00 & -4.00 & -5.65 & -5.30 & -4.87 & -5.70 & -5.33 & -4.81 & -5.32 & -4.76 & -4.27 \\
\hline & HCC2998 & -4.00 & -4.00 & -4.00 & -5.42 & -4.83 & -4.19 & -5.47 & -4.79 & -4.15 & -5.00 & -4.00 & -4.00 \\
\hline & HCT-116 & -5.55 & -5.16 & -4.00 & -5.60 & -4.93 & -4.07 & -5.61 & -4.98 & -4.36 & -5.43 & -4.00 & -4.00 \\
\hline & HCT-15 & -4.00 & -4.00 & -4.00 & -5.51 & -4.51 & -4.00 & -5.14 & -4.00 & -4.00 & -4.90 & -4.00 & -4.00 \\
\hline & HT-29 & -4.00 & -4.00 & -4.00 & -5.54 & -4.69 & -4.00 & -5.49 & -4.85 & -4.00 & -5.39 & -4.00 & -4.00 \\
\hline & KM12 & -5.29 & -4.00 & -4.00 & -5.47 & -4.72 & -4.00 & -5.49 & -4.91 & -4.39 & -5.22 & -4.00 & -4.00 \\
\hline & SW-620 & -5.41 & -4.00 & -4.00 & -5.48 & -4.38 & -4.00 & -5.48 & -4.84 & -4.38 & -5.36 & -4.00 & -4.00 \\
\hline \multirow{6}{*}{ CNS cancer } & SF-268 & -5.11 & -4.00 & -4.00 & -5.31 & -4.00 & -4.00 & -5.39 & -4.69 & -4.00 & -5.18 & -4.00 & -4.00 \\
\hline & SF-295 & -5.41 & -4.59 & -4.00 & -5.63 & -5.19 & -4.00 & -5.65 & -5.16 & -4.40 & -5.17 & -4.19 & -4.00 \\
\hline & SF-539 & -5.58 & - & -4.00 & -5.43 & -4.80 & -4.20 & -5.43 & -4.93 & -4.35 & -4.91 & -4.00 & -4.00 \\
\hline & SNB-19 & -5.08 & -4.00 & -4.00 & -5.39 & -4.00 & -4.00 & -5.45 & -4.00 & -4.00 & -5.25 & -4.00 & -4.00 \\
\hline & SNB-75 & -5.68 & -5.32 & -4.79 & -5.48 & -4.30 & -4.00 & -5.52 & -4.77 & -4.00 & -5.20 & -4.00 & -4.00 \\
\hline & U251 & -5.57 & -5.07 & -4.16 & -5.56 & -4.86 & -4.00 & -5.70 & -4.86 & -4.18 & -5.44 & -4.00 & -4.00 \\
\hline \multirow{9}{*}{ Melanoma } & LOX IMVI & -5.43 & -4.00 & -4.00 & -5.60 & -5.12 & -4.54 & -5.64 & -4.94 & -4.36 & -5.36 & -4.32 & -4.00 \\
\hline & MALME-3M & - & - & - & -5.73 & -5.38 & -5.03 & -5.71 & -5.25 & -4.47 & -5.39 & -4.37 & -4.00 \\
\hline & M14 & -5.16 & -4.00 & -4.00 & -5.43 & -4.00 & -4.00 & -5.48 & -4.89 & -4.13 & -5.20 & -4.00 & -4.00 \\
\hline & MDA-MB-435 & -5.31 & -4.00 & -4.00 & -5.53 & -4.91 & -4.00 & -5.49 & -4.59 & -4.00 & -5.39 & -4.00 & -4.00 \\
\hline & SK-MEL-2 & -5.47 & -4.00 & -4.00 & -5.61 & -5.27 & -4.57 & -5.51 & -5.06 & -4.00 & -5.07 & -4.28 & -4.00 \\
\hline & SK-MEL-28 & - & -4.00 & -4.00 & -5.48 & -4.84 & -4.22 & -5.31 & -4.68 & -4.10 & -5.09 & -4.00 & -4.00 \\
\hline & SK-MEL-5 & -5.62 & -5.09 & -4.00 & -5.77 & -5.48 & -5.19 & -5.86 & -5.56 & -5.26 & -5.37 & -4.76 & -4.25 \\
\hline & UACC-257 & - & -4.00 & -4.00 & -5.52 & -5.01 & -4.00 & -5.55 & -4.97 & -4.00 & -5.09 & -4.00 & -4.00 \\
\hline & UACC-62 & -5.50 & -4.00 & -4.00 & -5.76 & -5.40 & -5.04 & -5.75 & -5.27 & -4.62 & -5.18 & -4.07 & -4.00 \\
\hline \multirow{7}{*}{$\begin{array}{l}\text { Ovarian } \\
\text { cancer }\end{array}$} & IGROV1 & -5.36 & -4.63 & -4.00 & -5.48 & -4.58 & -4.00 & -5.46 & -4.00 & -4.00 & -4.95 & -4.00 & -4.00 \\
\hline & OVCAR-3 & -5.61 & -5.27 & -4.10 & -5.53 & -4.67 & -4.00 & -5.58 & -5.01 & -4.50 & -5.41 & -4.00 & -4.00 \\
\hline & OVCAR-4 & -5.55 & -5.14 & -4.00 & -5.52 & -4.00 & -4.00 & -5.47 & -4.00 & -4.00 & -5.07 & -4.00 & -4.00 \\
\hline & OVCAR-5 & - & -4.00 & -4.00 & -5.47 & -4.00 & -4.00 & - & - & - & -4.63 & -4.00 & -4.00 \\
\hline & OVCAR-8 & -5.53 & -4.89 & -4.00 & -5.64 & -4.00 & -4.00 & -5.65 & -4.63 & -4.00 & -5.37 & -4.00 & -4.00 \\
\hline & NCl/ADR-RES & -5.38 & -4.00 & -4.00 & -5.23 & -4.00 & -4.00 & -4.24 & -4.00 & -4.00 & -4.28 & -4.00 & -4.00 \\
\hline & SK-OV-3 & -5.67 & -5.28 & -4.27 & -5.43 & -4.75 & -4.00 & -5.50 & -4.36 & -4.00 & -4.59 & -4.00 & -4.00 \\
\hline
\end{tabular}


Continuation of Table 2

\begin{tabular}{|c|c|c|c|c|c|c|c|c|c|c|c|c|c|}
\hline 1 & 2 & 3 & 4 & 5 & 6 & 7 & 8 & 9 & 10 & 11 & 12 & 13 & 14 \\
\hline \multirow{8}{*}{ Renal Cancer } & $786-0$ & -5.69 & -5.37 & - & -5.43 & -4.73 & -4.00 & -5.41 & -4.80 & -4.20 & -5.27 & -4.13 & -4.00 \\
\hline & A498 & -5.52 & -4.00 & -4.00 & -5.78 & -5.23 & -4.00 & -5.53 & -5.03 & -4.00 & -5.70 & -4.65 & -4.00 \\
\hline & $\mathrm{ACHN}$ & -5.72 & -5.38 & -5.04 & -5.50 & -4.00 & -4.00 & - & - & - & -5.37 & -4.00 & -4.00 \\
\hline & CAKI-1 & -5.44 & -4.00 & -4.00 & -5.48 & -4.00 & -4.00 & -5.38 & -4.59 & -4.00 & -4.82 & -4.00 & -4.00 \\
\hline & RXF 393 & -5.67 & -5.22 & -4.21 & -5.65 & -5.13 & -4.44 & -5.63 & -5.02 & -4.37 & -5.62 & -5.08 & -4.21 \\
\hline & SN12C & -5.30 & -4.00 & -4.00 & -5.52 & -4.60 & -4.00 & -5.65 & -4.86 & -4.00 & -5.36 & -4.00 & -4.00 \\
\hline & TK-10 & -5.55 & -5.18 & -4.00 & -5.50 & -4.00 & -4.00 & -5.40 & -4.37 & -4.00 & -5.15 & -4.13 & -4.00 \\
\hline & UO-31 & -5.70 & -5.38 & - & -5.55 & -4.95 & -4.14 & -5.44 & -4.74 & -4.00 & -5.42 & -4.66 & -4.00 \\
\hline \multirow{2}{*}{$\begin{array}{l}\text { Prostate } \\
\text { cancer }\end{array}$} & $P C-3$ & -5.38 & -4.00 & -4.00 & -5.74 & -5.07 & -4.00 & -5.60 & -4.00 & -4.00 & -5.52 & -4.00 & -4.00 \\
\hline & DU-145 & -5.08 & -4.00 & -4.00 & -5.47 & -4.00 & -4.00 & -5.55 & -4.82 & -4.00 & -5.01 & -4.00 & -4.00 \\
\hline \multirow{6}{*}{ Breast cancer } & MCF7 & -5.33 & -4.00 & -4.00 & -5.51 & -4.00 & -4.00 & -5.53 & -4.00 & -4.00 & -5.39 & -4.00 & -4.00 \\
\hline & $\begin{array}{c}\text { MDA- } \\
\text { MB-231/ATCC }\end{array}$ & -5.62 & -5.15 & -4.00 & -5.68 & -5.30 & -4.39 & -5.64 & -5.13 & -4.17 & -5.35 & -4.40 & -4.00 \\
\hline & HS 578T & -5.37 & -4.00 & -4.00 & -5.59 & -4.54 & -4.00 & -5.38 & -4.08 & -4.00 & -5.36 & -4.00 & -4.00 \\
\hline & BT-549 & -4.50 & -4.00 & -4.00 & -5.42 & -4.51 & -4.00 & -5.44 & -5.02 & -4.42 & -5.25 & -4.00 & -4.00 \\
\hline & T47D & -5.43 & -4.00 & -4.00 & -5.54 & -4.00 & -4.00 & -5.64 & -4.00 & -4.00 & -5.41 & -4.00 & -4.00 \\
\hline & MDA-MB-468 & -5.57 & -5.05 & -4.00 & -5.85 & -5.26 & -4.00 & -5.94 & -5.07 & -4.12 & -5.57 & -4.73 & -4.00 \\
\hline
\end{tabular}

The melting points were measured on a small-sized heating table with a RNMK 05 observation device (VEB Analytik, Dresden).

The general procedure for the synthesis of 1-phenyl-4-aryl-5,6,7,8-tetrahydro-2,2a,8atriazacyclopenta $[\boldsymbol{c d}]$ azulenes $7 \mathbf{a - k}$. Boil the mixture of 0.01 Mole of the appropriate 3-aryl-6,7,8,9tetrahydro-5H-[1,2,4]triazole [4,3-a]azepine $\mathbf{4} \mathbf{a}, \mathbf{b}$ and 0.01 Mole of the substituted phenacyl bromide $\mathbf{5}$ in $80 \mathrm{ml}$ of ethyl acetate for 1 hour. After cooling decant the solvent, wash the residue - quarternary salt $6 \mathbf{a}-\mathbf{k}$ - with the ester, add $40 \mathrm{ml}$ of $5 \% \mathrm{NaOH}$ solution and boil the reaction mixture for 3 hours. After cooling filter the precipitate, wash with water, then dry in air and recrystallize from benzene.

1,4-diphenyl-5,6,7,8-tetrahydro-2,2a,8atriazacyclopenta[ $\boldsymbol{c d}]$ ]azulene 7a. Yield $-1.19 \mathrm{~g}(38 \%)$. M. p. $-189-191{ }^{\circ} \mathrm{C}$ (from benzene). Anal. Calcd. for $\mathrm{C}_{21} \mathrm{H}_{19} \mathrm{~N}_{3}$ \%: N 13.4. Found, \%: N 13.2. ${ }^{1} \mathrm{H}$ NMR $(300 \mathrm{MHz}$, DMSO-d ${ }_{6}$ ), $\delta$ (ppm): $2.01\left(\mathrm{~m}, 4 \mathrm{H}, 6,7-\mathrm{CH}_{2} \mathrm{CH}_{2}\right.$ ), 2.80 $\left(\mathrm{m}, 2 \mathrm{H}, 5-\mathrm{CH}_{2}\right), 4.08\left(\mathrm{~m}, 2 \mathrm{H}, 8-\mathrm{CH}_{2}\right), 7.24(\mathrm{~s}, 1 \mathrm{H}, 3-\mathrm{H})$, 7.49-7.81 (m, 10H, 2Ph).

1-Phenyl-4-(para-tolyl)-5,6,7,8-tetrahydro2,2a,8a-triazacyclopenta[cd] azulene 7b. Yield - $1.41 \mathrm{~g}$ (43 \%). M. p. $-190-192^{\circ} \mathrm{C}$ (from benzene). Anal. Calcd. for $\mathrm{C}_{22} \mathrm{H}_{21} \mathrm{~N}_{3}$. \%: N 12.8. Found, \%: N 13.1, ${ }^{1} \mathrm{H}$ NMR (300 MHz, DMSO-d $\mathrm{d}_{6}$ ), $\delta$ (ppm): $2.00\left(\mathrm{~m}, 4 \mathrm{H}, 6,7-\mathrm{CH}_{2} \mathrm{CH}_{2}\right.$ ), $2.31\left(\mathrm{c}, 3 \mathrm{H}, \mathrm{CH}_{3}\right), 2.81\left(\mathrm{~m}, 2 \mathrm{H}, 5-\mathrm{CH}_{2}\right), 4.08(\mathrm{~m}, 2 \mathrm{H}$, 8- $\left.\mathrm{CH}_{2}\right), 7.17$ and $7.37\left(\mathrm{~d}-\mathrm{d}, 4 \mathrm{H}, \mathrm{C}_{6} \mathrm{H}_{4}\right), 7.22(\mathrm{~s}, 1 \mathrm{H}, 3-\mathrm{H})$, 7.57-7.80 (m, 5H, Ph).

1-Phenyl-4-( ${ }^{1}$-methoxyphenyl)-5, 6,7,8tetrahydro-2,2a,8a-triazacyclopenta[cd]azulene 7c. Yield - 1.75 g (51 \%). M. p. $-181-182{ }^{\circ} \mathrm{C}$ (from benzene). Anal. Calcd. for $\mathrm{C}_{22} \mathrm{H}_{21} \mathrm{~N}_{3} \mathrm{O} . \%$ : N 12.2.
Found, \%: N 12.5. ${ }^{1} \mathrm{H}$ NMR (300 MHz, DMSO-d $\left.{ }_{6}\right), \delta(\mathrm{ppm})$ : $2.01\left(\mathrm{~m}, 4 \mathrm{H}, 6,7-\mathrm{CH}_{2} \mathrm{CH}_{2}\right), 2.78\left(\mathrm{~m}, 2 \mathrm{H}, 5-\mathrm{CH}_{2}\right), 3.77$ $\left(\mathrm{s}, 3 \mathrm{H}, \mathrm{OCH}_{3}\right), 4.08\left(\mathrm{~m}, 2 \mathrm{H}, 8-\mathrm{CH}_{2}\right), 6.94$ and 7.41 (d-d, $\left.4 \mathrm{H}, \mathrm{C}_{6} \mathrm{H}_{4}, \mathrm{~J}=8.7 \mathrm{~Hz}\right), 7.21(\mathrm{~s}, 1 \mathrm{H}, 3-\mathrm{H}), 7.56-7.81(\mathrm{~m}$, $5 \mathrm{H}, \mathrm{Ph}$ ).

1-Phenyl-4-(4 ${ }^{1}$-ethoxyphenyl)-5,6,7,8-tetrahydro-2,2a,8a-triazacyclopenta[cd]azulene $7 \mathrm{~d}$. Yield - 1.32 g (37 \%). M. p. $-197-198{ }^{\circ} \mathrm{C}$ (from benzene). Anal. Calcd. for $\mathrm{C}_{23} \mathrm{H}_{23} \mathrm{~N}_{3} \mathrm{O}$. \%: $\mathrm{N} 11.8$. Found, \%: N 12.1. ${ }^{1} \mathrm{H}$ NMR (300 MHz, DMSO-d $\mathrm{d}_{6}$ ), $\delta$ (ppm): 1.35 $\left(\mathrm{t}, 3 \mathrm{H}, \mathrm{CH}_{3}\right), 2.05\left(\mathrm{~m}, 4 \mathrm{H}, 6,7-\mathrm{CH}_{2} \mathrm{CH}_{2}\right), 2.80(\mathrm{~m}, 2 \mathrm{H}$, 5- $\left.\mathrm{CH}_{2}\right), 4.05\left(\mathrm{q}, 2 \mathrm{H}, \mathrm{CH}_{2}\right), 4.08\left(\mathrm{~m}, 2 \mathrm{H}, 8-\mathrm{CH}_{2}\right), 6.89$ and $7.31\left(\mathrm{~d}-\mathrm{d}, 4 \mathrm{H}, \mathrm{C}_{6} \mathrm{H}_{4}, \mathrm{~J}=8.4 \mathrm{~Hz}\right), 7.09(\mathrm{~s}, 1 \mathrm{H}, 3-\mathrm{H})$, 7.53-7.78 (m, 5H, Ph).

1-Phenyl-4-(2,3-dehydrobenzene [1,4]dioxane-6-yl)-5,6,7,8-tetrahydro-2,2a,8a-triazacyclopenta[cd]azulene 7e. Yield - $1.30 \mathrm{~g} \mathrm{(35 \% ).}$ M. p. $-152-153{ }^{\circ} \mathrm{C}$ (from benzene). Anal. Calcd. for $\mathrm{C}_{23} \mathrm{H}_{21} \mathrm{~N}_{3} \mathrm{O}_{2} . \%$ : N 11.3. Found, \%: N 11.5. ${ }^{1} \mathrm{H}$ NMR $(300 \mathrm{MHz}$, DMSO-d $\left.{ }_{6}\right), \delta(\mathrm{ppm}): 1.86-2.00\left(\mathrm{~m}, 4 \mathrm{H}, 6,7-\mathrm{CH}_{2} \mathrm{CH}_{2}\right)$, $2.75\left(\mathrm{~m}, 2 \mathrm{H}, 5-\mathrm{CH}_{2}\right), 3.70\left(\mathrm{~m}, 2 \mathrm{H}, 8-\mathrm{CH}_{2}\right), 4.24(\mathrm{~m}, 4 \mathrm{H}$, - $\left.\mathrm{OCH}_{2} \mathrm{CH}_{2} \mathrm{O}-\right)$, 6.80-6.87 (m, 3H, $\left.\mathrm{C}_{6} \mathrm{H}_{3}\right), 7.28(\mathrm{~s}, 1 \mathrm{H}, 3-\mathrm{H})$, 7.40-7.51 (m, 5H, Ph).

1-Phenyl-4-( $4^{1}$-chlorophenyl)-5,6,7,8-tetrahydro-2,2a,8a-triazacyclopenta[cd]azulene $7 \mathrm{f}$. Yield - 1.43 g (43 \%). M. p. - 208-209 ${ }^{\circ} \mathrm{C}$ (from benzene). Anal. Calcd. for $\mathrm{C}_{21} \mathrm{H}_{18} \mathrm{ClN}_{3}$. \%: N 12.1. Found, \%: N 12.2. ${ }^{1} \mathrm{H}$ NMR (300 MHz, DMSO- $\mathrm{d}_{6}$ ), $\delta$ (ppm): 2.01 $\left(\mathrm{m}, 4 \mathrm{H}, 6,7-\mathrm{CH}_{2} \mathrm{CH}_{2}\right), 2.80\left(\mathrm{~m}, 2 \mathrm{H}, 5-\mathrm{CH}_{2}\right), 4.08(\mathrm{~m}, 2 \mathrm{H}$, 8- $\left.\mathrm{CH}_{2}\right), 7.36(\mathrm{~s}, 1 \mathrm{H}, 3-\mathrm{H}), 7.38-7.80\left(\mathrm{~m}, 9 \mathrm{H}, \mathrm{C}_{6} \mathrm{H}_{4}+\mathrm{Ph}\right)$.

1-Phenyl-4-( $4^{1}$-bromophenyl)-5,6,7,8-tetrahydro-2,2a,8a-triazacyclopenta[cd]azulene $7 \mathrm{~g}$. Yield - 2.31 g (59 \%). M. p. - $214-216{ }^{\circ} \mathrm{C}$ (from benzene). Anal. Calcd. for $\mathrm{C}_{21} \mathrm{H}_{18} \mathrm{BrN}_{3}$ \%: $\mathrm{N}$ 10.7. Found, \%: 
N 10.9. ${ }^{1} \mathrm{H}$ NMR (300 MHz, DMSO-d $\left.\mathrm{d}_{6}\right), \delta$ (ppm): 2.00 (m, 4H, 6,7- $\left.\mathrm{CH}_{2} \mathrm{CH}_{2}\right), 2.80\left(\mathrm{~m}, 2 \mathrm{H}, 5-\mathrm{CH}_{2}\right), 4.07(\mathrm{~m}, 2 \mathrm{H}$, $\left.8-\mathrm{CH}_{2}\right), 7.35(\mathrm{~s}, 1 \mathrm{H}, 3-\mathrm{H}), 7.46$ and $7.51\left(\mathrm{~d}-\mathrm{d}, 4 \mathrm{H}, \mathrm{C}_{6} \mathrm{H}_{4}\right.$, $\mathrm{J}=8.4 \mathrm{~Hz}), 7.56-7.80(\mathrm{~m}, 5 \mathrm{H}, \mathrm{Ph})$.

1-(4'-bromphenyl)-4-(para-tolyl)-5,6,7,8-tetrahydro-2,2a,8a-triazacyclopenta[cd]azulene $7 \mathrm{~h}$. Yield - 1.91 g (47 \%). M. p. - 197-198 ${ }^{\circ} \mathrm{C}$. Anal. Calcd. for $\mathrm{C}_{22} \mathrm{H}_{20} \mathrm{BrN}_{3}$ \%: $\mathrm{Br} 19.7, \mathrm{~N} 10.3$. Found, \%: $\mathrm{Br} 19.4$, $\mathrm{N}$ 10.2. ${ }^{1} \mathrm{H}$ NMR (300 MHz, DMSO-d $\left.\mathrm{d}_{6}\right), \delta$ (ppm): 2.01 $\left(\mathrm{m}, 4 \mathrm{H}, 6,7-\mathrm{CH}_{2} \mathrm{CH}_{2}\right), 2.30\left(\mathrm{~s}, 3 \mathrm{H}, \mathrm{CH}_{3}\right), 2.80(\mathrm{~m}, 2 \mathrm{H}$, $\left.5-\mathrm{CH}_{2}\right), 4.08\left(\mathrm{~m}, 2 \mathrm{H}, 8-\mathrm{CH}_{2}\right), 7.24(\mathrm{~s}, 1 \mathrm{H}, 3-\mathrm{H}), 7.16$ and 7.37 (d-d, $4 \mathrm{H}, \mathrm{C}_{6} \mathrm{H}_{4}, \mathrm{~J}=8.1 \mathrm{~Hz}$ ), 7.74 and 7.78 (d-d, $\left.4 \mathrm{H}, \mathrm{C}_{6} \mathrm{H}_{4}, \mathrm{~J}=8.7 \mathrm{~Hz}\right)$.

1-(4 ${ }^{1}$-bromophenyl)-4-(42-difluoromethoxyphenyl)-5,6,7,8-tetrahydro-2,2a,8a-triazacyclopenta[cd]azulene 7i. Yield - 2.38 g (52 \%). M. p. $-203-204{ }^{\circ} \mathrm{C}$ (from pyridine). Anal. Calcd. for $\mathrm{C}_{22} \mathrm{H}_{18} \mathrm{BrF}_{2} \mathrm{~N}_{3} \mathrm{O}$. \%: N 9.16. Found, \%: $\mathrm{N}$ 9.28. ${ }^{1} \mathrm{H}$ NMR (300 MHz, DMSO-d $), \delta$ (ppm): $2.05\left(\mathrm{~m}, 4 \mathrm{H}, 6,7-\mathrm{CH}_{2} \mathrm{CH}_{2}\right.$ ), $2.82\left(\mathrm{~m}, 2 \mathrm{H}, 5-\mathrm{CH}_{2}\right), 4.08\left(\mathrm{~m}, 2 \mathrm{H}, 8-\mathrm{CH}_{2}\right), 7.08(\mathrm{t}, 1 \mathrm{H}$, $\left.\mathrm{OCHF}_{2}, \mathrm{~J}=73 \mathrm{~Hz}\right), 7.23(\mathrm{~s}, 1 \mathrm{H}, 3-\mathrm{H}), 7.72\left(\mathrm{~s}, 4 \mathrm{H}, \mathrm{C}_{6} \mathrm{H}_{4}\right)$.

1-(4 ${ }^{1}$-bromophenyl)-4-(3 $3^{2}, 4^{2}$-dimethoxyphenyl)-5,6,7,8-tetrahydro-2,2a,8a-triazacyclopenta[cd] azulene 7j. Yield -1.76 g(39\%). M. p. $-191-192^{\circ} \mathrm{C}$ (from toluene). Anal. Calcd. for $\mathrm{C}_{23} \mathrm{H}_{22} \mathrm{BrN}_{3} \mathrm{O}_{2}$. Calcd., \%: Br 17.7, N 9.28. Found, \%: Br 17.4, N 9.35. ${ }^{1} \mathrm{H}$ NMR (300 MHz, DMSO-d $), \delta$ (ppm): $2.02\left(\mathrm{~m}, 4 \mathrm{H}, 6,7-\mathrm{CH}_{2} \mathrm{CH}_{2}\right.$ ), $2.80\left(\mathrm{~m}, 2 \mathrm{H}, 5-\mathrm{CH}_{2}\right), 3.76\left(\mathrm{~s}, 3 \mathrm{H}, \mathrm{OCH}_{3}\right), 3.80(\mathrm{~s}, 3 \mathrm{H}$,
$\left.\mathrm{OCH}_{3}\right), 4.08\left(\mathrm{~m}, 2 \mathrm{H}, 8-\mathrm{CH}_{2}\right), 6.93-7.05\left(\mathrm{~m}, 3 \mathrm{H}, \mathrm{C}_{6} \mathrm{H}_{3}\right)$, $7.24(\mathrm{~s}, 1 \mathrm{H}, 3-\mathrm{H}), 7.73$ and 7.78 (d-d, $\left.4 \mathrm{H}, \mathrm{C}_{6} \mathrm{H}_{4} \mathrm{~J}=9.3 \mathrm{~Hz}\right)$.

1-(41-bromphenyl)-4-(2,3-de-hydrobenzene [1,4]dioxane-6-yl)-5,6,7,8-tetrahydro-2,2a,8atriazacyclopenta[cd] azulene 7k. Yield - $1.76 \mathrm{~g}(39 \%)$. M. p. $-212-213{ }^{\circ} \mathrm{C}$ (from toluene). Anal. Calcd. for $\mathrm{C}_{23} \mathrm{H}_{20} \mathrm{BrN}_{3} \mathrm{O}_{2}$. \%: $\mathrm{Br}$ 17.7, $\mathrm{N}$ 9.33. Found, \%: $\mathrm{Br} 17.9$, N 9.52. ${ }^{1} \mathrm{H}$ NMR (300 MHz, DMSO-d $\left.\mathrm{d}_{6}\right), \delta$ (ppm): 2.01 (m, 4H, 6,7- $\left.\mathrm{CH}_{2} \mathrm{CH}_{2}\right), 2.77\left(\mathrm{~m}, 2 \mathrm{H}, 5-\mathrm{CH}_{2}\right), 4.09(\mathrm{~m}, 2 \mathrm{H}$, 8- $\left.\mathrm{CH}_{2}\right), 4.24\left(\mathrm{~m}, 4 \mathrm{H}, \mathrm{OCH}_{2} \mathrm{CH}_{2} \mathrm{O}-\right), 6.81-6.92(\mathrm{~m}, 3 \mathrm{H}$, $\left.\mathrm{C}_{6} \mathrm{H}_{3}\right), 7.18(\mathrm{~s}, 1 \mathrm{H}, 3-\mathrm{H}), 7.72$ and $7.79\left(\mathrm{~d}-\mathrm{d}, 4 \mathrm{H}, \mathrm{C}_{6} \mathrm{H}_{4}\right.$, $\mathrm{J}=9.3 \mathrm{~Hz}$ ).

\section{Conclusions}

1. New chemical compounds - derivatives of 1 1-phenyl-4-aryl-5, 6,7,8-tetrahydro-2,2a,8atriazacyclopenta[cd] azulenes 7a-g and 1-(41-bromphenyl)-4-aryl-5,6,7,8-tetrahydro-2,2a,8a-triazacyclopenta[cd]azulenes $\mathbf{7 h}$-k showing the antineoplastic activity have been synthesized.

2 . The compounds, which are characterized by the high level of effective inhibition of leukemia, nonsmall cell lung cancer, colon cancer, CNS cancer, melanoma, ovarian cancer, renal cancer, prostate cancer and breast cancer, have been identified for the in-depth preclinical studies.

Conflict of interests: authors have no conflict of interests to declare.

\section{References}

1. Терегулова, Д. Р. Влияние полихимиотерапии на когнитивные функции у пациентов с лимфопролиферативными заболеваниями: обзор литературы и собственные клинические наблюдения / Д. Р. Терегулова, Б. А. Бакиров, Л. Р. Ахмадеева // Пермский медицинский журн. - 2018. - Т. 35, № 6. - С. 73-81. https://doi.org/10.17816/pmj35673-81

2. Анализ результатов лечения пациентов детского возраста с раком носоглотки: ретроспективное когортное исследование / Т. В. Горбунова, Али А. Абдулрахман, И. В. Глеков и др. // Онкопедиатрия. - 2018. - № 5 (4). - C. 257-267. https://doi.org/10.15690/onco.v5i4.1969

3. Протипухлинні засоби. [Електронний ресурс] // DMUPharm. Non scholae, sed vitae discimusa. - Режим доступу : http://dmupharm.pp.ua/ index. php/temi/20-khimioterapevtichni-zasobi-riznikh-grup/228-protipukhlinni-zasobi.

4. Кравченко, Т. В. Біологічна активність похідних 1,2,4-триазолу / Т. В. Кравченко, О. І. Панасенко, Є. Г. Книш // Фарм. журн. - 2016. № 5. - C. 25-30.

5. Letrozole therapy alone or in sequence with tamoxifen in women with breast cancer / H. Mouridsen, A. Giobbie-Hurder, A. Goldhirsch et al. // Engl. J. Med. - 2009. - Vol. 361 (8). - P. 766-776. https://doi.org/10.1056/nejmoa0810818

6. A randomized phase II study of letrozole vs. observation in patients with newly diagnosed uterine leiomyosarcoma (uLMS) / M. B. Slomovitza, M. C. Tauba, M. Huanga et al. // Gynecologic Oncology Reports. - 2019. - Vol. 27. - P. 1-4. https://doi.org/10.1016/j.gore.2018.11.001

7. Anastrozole alone or in combination with tamoxifen versus tamoxifen alone for adjuvant treatment of postmenopausal women with early stage breast cancer. Results of the ATAC (Arimidex, Tamoxifen Alone or in Combination) trial efficacy and safety update analyses / The ATAC (Arimidex, Tamoxifen Alone or in Combination) Trialists' Group // Howell Cancer. - 2003. - Vol. 98. - P. 1802-1810. https://doi.org/10.1056/nejmoa0810818

8. Поворознюк, В. В. Остеопороз при злоякісних новоутвореннях / В. В. Поворознюк, М. А. Бистрицька, А. С. Мусіенко // Боль. Суставы. Позвоночник. - 2018. - № 8 (2). С. 101-110. https://doi.org/10.22141/2224-1507.8.2.2018.137192

9. “World Cancer Report”. [Електронний ресурс] : / International Agency for Research on Cancer. - 2008. - Режим доступу : https://www.who. int/cancer/publications/world_cancer_report2008/en/

10. Beverly, A. Andrews. Anticancer drug development guide : preclinical screening, clinical / A. Beverly, P. A. Teicher // Medical. - 2004. - 450 p.

11. Feasibility of drug screening with panels of human tumor cell lines using a microculture Tetrazolium assay / M. C. Alley, D. A. Scudiero, P. A. Monks et al. // Cancer Res. -1988. - Vol. 48. - P. 589-601.

12. Photochemically enhanced binding of small molecules to the tumor necrosis factor receptor-1 inhibits the binding of TNF- $\alpha$ / P. H. Carter, P. A. Scherle, J. A. Muckelbauer et al. // Proc. Natl. Acad. Sci. USA. - 2001. - Vol. 98. - P. 11879-11886. https://doi.org/10.1073/pnas.211178398

13. Grever, M. R. The National Cancer Institute : cancer drug discovery and development program / M. R. Grever, S. A. Schepartz, B. A. Chabner // Seminars in Oncol. - 1992. - Vol. 19, № 6. - P. 622-638.

14. Ацетали лактамов. VII. Исследование алкилирования N-метиллактамов и лактимных эфиров диметилсульфатом // В. Г. Граник, А. М. Жидкова, Н. С. Курятов и др. // ХГС. - 1973. - № 11. - С. 1532-1535.

15. Siegfried Petersen and Ernst Tietze. Reaktionen Cyclischer Lactimäther mit Acylierten Hydrazinderivaten // Chem. Ber. - 1957. - Vol. 90., Issue 6. P. 909-921. https://doi.org/10.1002/cber.19570900609 


\section{References}

1. Teregulova, D. R., Bakirov, B. A., \& Akhmadeeva, L. R. (2018). Influence of polychemotherapy on cognitive functions in patients with lymphoproliferative diseases : literature review and personal clinical observations. Perm Medical Journal, 35 (6), 73-81. https://doi.org/10.17816/pmj35673-81

2. Gorbunova, T. V., Abdulrahman Ali, A.-A. G., Glekov, I. V., Susuleva, N. A., Shishkov, R. V., Ivanova, N. V., \& Polyakov, V. G. (2018). Analysis of Treatment of the Outcomes in Pediatric Patients With Nasopharyngeal Cancer: A Retrospective Cohort Study. Oncopediatrics, 5 (4), 257-267. https:// doi.org/10.15690/onco.v5i4.1969

3. Protipuhlinni zasobi. DMUPharm. Non scholae, sed vitae discimus. Available at: http://dmupharm.pp.ua/index.php/temi/20-khimioterapevtichni-zasobi-riznikh-grup/228protipukhlinni-zasobi

4. Kravchenko, T. V., Panasenko, O. I., Knish, Ye. G. (2016). Farmacevtichnij zhurnal, 5, 25-30.

5. Mouridsen, H. Giobbie-Hurder, A., Goldhirsch A., Thürlimann B., Paridaens R, Smith I, Coates, A. S. (2009). Letrozole therapy alone or in sequence with tamoxifen in women with breast cancer. The New England Journal of Medicine, 361 (8), 766-776. https://doi.org/10.1056/nejmoa0810818

6. Slomovitz, B. M., Taub, M. C., Huang, M., Levenback, C., \& Coleman, R. L. (2019). A randomized phase II study of letrozole vs. observation in patients with newly diagnosed uterine leiomyosarcoma (uLMS). Gynecologic Oncology Reports, 27, 1-4. https://doi.org/10.1016/j.gore.2018.11.001

7. The ATAC (Arimidex, Tamoxifen Alone or in Combination) Trialists' Group (2003). Anastrozole alone or in combination with tamoxifen versus tamoxifen alone for adjuvant treatment of postmenopausal women with early-stage breast cancer. Cancer, 98(9), 1802-1810. https:// doi.org/10.1056/nejmoa0810818

8. Povoroznyuk, V. V., Bystrytska, M. A., \& Musiienko, A. S. (2018). Osteoporosis in oncology. PAIN. JOINTS. SPINE, 8 (2), 101-110. https:// doi.org/10.22141/2224-1507.8.2.2018.137192

9. "World Cancer Report". (2008). International Agency for Research on Cancer. Retrieved 2011-02-26. (cancer statistics often exclude non-melanoma skin cancers such as basal cell carcinoma, which are common but rarely fatal). URL: https://www.who.int/cancer/publications/world_cancer_report2008/en/

10. Beverly A. Teicher, Paul A. Andrews. (Eds). (2004). Anticancer drug development guide: preclinical screening, clinical. Medical, $1,450$.

11. Alley M.C, Scudiero, D. A., Monks, P. A., Hursey, M. L., Czerwinski, M. J., Fine, D. L., Abbott, B. J., Mayo, J. G., Shoemaker, R. H., Boyd, M. R. (1988). Feasibility of drug screening with panels of human tumor cell lines using a microculture Tetrazolium assay. Cancer Res, 48, $589-601$.

12. Carter, P. H., Scherle, P. A., Muckelbauer, J. A., Voss, M. E., Liu, R.-Q., Thompson, L. A., ... Decicco, C. P. (2001). Photochemically enhanced binding of small molecules to the tumor necrosis factor receptor-1 inhibits the binding of TNF. Proceedings of the National Academy of Sciences, 98 (21), 11879-11884. https://doi.org/10.1073/pnas.211178398

13. Grever, M. R., Schepartz, S. A., Chabner, B. A. (1992). The National Cancer Institute : cancer drug discovery and development program. Seminars in Oncol, 19 (6), 622-638.

14. Granik, V. G., Zhidkova, A. M., Kuryatov, N. (1973). HGS, 11, 1532-1535.

15. Petersen, S., \& Tietze, E. (1957). Reaktionen Cyclischer Lactimäther mit Acylierten Hydrazinderivaten. Chemische Berichte, 90 (6), 909-921. https://doi.org/10.1002/cber.19570900609 